\title{
Korneal Arkus Senilis Olgularında, Gri Skala ve Spektral Doppler Ultrasonografi ile Karotis Arter Değerlendirilmesi
}

\section{Evaluation of Carotid Artery by Gray Scale and Spectral Doppler Ultrasonography in Cases with Corneal Arcus Senile}

\author{
Yelda YILDIZ TAŞÇıI, Özlem ÜNAL ${ }^{2}$ \\ 1 Ankara Şehir Hastanesi, Göz Hastalıkları Kliniği, Ankara, Türkiye \\ 2 Ankara Yıldırım Beyazıt Üniversitesi Tıp Fakültesi, Radyoloji Anabilim Dalı, Ankara, Türkiye
}

Yazışma Adresi

Correspondence Address

Yelda YILDIZ TAŞÇI

Correspondence Address

Ankara Şehir Hastanesi, Göz

Hastalıkları Kliniği, Ankara, Türkiye

yeldayldz83@gmail.com

Geliş tarihi / Received : Ocak 18, 2021 Kabul tarihi / Accepted : Nisan 30, 2021 Elektronik yayın tarihi : Ocak 01, 2022 Online published

Bu makalede yapılacak atıf:

Cite this article as:

Yıldız Taşçı Y, Ünal Ö.

Korneal Arkus Senilis Olgularında,

Gri Skala ve Spektral

Doppler Ultrasonografi ile Karotis

Arter Değerlendirilmesi.

Akd Tip D 2022; 8(1):42-47.

Yelda Yıldız Taşçı

ORCID ID: 0000-0003-2741-1646

Özlem Ünal

ORCID ID: 0000-0003-4297-4930

\section{ÖZ}

Amaç:

Bu çalışmada korneal arkus senilis olan hastalarda gri skala ultrasonografi ve spektral analizli renkli doppler ultrasonografi ile ana karotis arter değerlendirilmesini amaçladık.

\section{Yöntemler:}

Çalışmaya dahil edilen tüm korneal arkus senilisli hastalara detaylı bir oftalmolojik muayene yapıldıktan sonra tam kan sayımı, kan lipid profili, gri skala ultrasonografi ve spektral analizli renkli doppler ultrasonografi ile ana karotis arter değerlendirilmesi yapıldı.

\section{Bulgular:}

Çalışmaya 32 hastanın 64 gözü dahil edildi. Ortalama yaş 64,9 $\pm 9,52$ (49-85) yıl ve kadın erkek oranı $10(\% 30)$ / $22(\% 70)$ idi. Tüm gözlerde arkus senilis bilateral, halka şeklindeydi ve hafif, orta, yoğun arkus senilis oranı sırasıyla $\% 22, \% 26, \% 52$ idi.

Arkus senilisli hastaların kandaki total kolesterol, TG, LDL, VLDL değerleri referans değerlere göre yüksekti. Arkus senilisin yoğunluğu arttıkça ana karotis arter intima-media kalınlığının arttığı gözlendi ve istatistiksel olarak anlamlı bulundu $(\mathrm{p}<0.05)$. Arkus senilisli olgularda ana karotis arter gri skala ultrasonografide $\% 61$ oranında plak tespit edildi ve bunların $\% 65$ 'i yumuşak karakterliydi. Arkus senilis yoğunluğu ile vücut kitle indeksi, sigara kullanımı, nötrofil-lenfosit oranı ve kan lipid profili arasında bir istatistiksel olarak anlamlı bir ilişki bulunmadı $(\mathrm{p}>0.05)$.

\section{Sonuç:}

Korneal arkus senilis olgularında, ana karotis arterde intima-media kalınlığının ve plak oluşumunun arttığı gözlemlendi. Daha fazla hasta sayısına ihtiyaç duymakla beraber, korneal arkus senilisin kardiyovasküler ve serebrovasküler hastalıklar için bağımsız bir risk faktörü olabileceğini söyleyebiliriz.

Anahtar Sözcükler: Arkus senilis, Karotis arter, Ultrasonografi

\section{ABSTRACT \\ Objective:}

In this study, we aimed to evaluate the common carotid artery by gray scale ultrasonography and spectral analysis color doppler ultrasonography in patients with corneal arcus senilis.

\section{Methods:}

After a detailed ophthalmologic examination of patients who included in the study with corneal 
Yıldız Taşçı Y. ve Ünal Ö.

arcus senilis, blood count, blood lipid profile, gray scale ultrasonography and spectral analysis color doppler ultrasonography evaluation of common carotid artery were performed.

\section{Results:}

64 eyes of 32 patients were included in the study. The mean age was $64.69 \pm 9.5(49-85)$ years, and the female to male ratio was $10(30 \%) / 22(70 \%)$. In all eyes, the arcus senilis was bilateral and ring-shaped, and the rate of mild, moderate, dense arcus senilis was $22 \%, 26 \%, 52 \%$, respectively. Total cholesterol, TG,LDL, VLDL values of the patients with arcus senilis were higher than the reference values. It was observed that intima-media thickness of the common carotid artery increased correlated with the density of the archus senilis and it was found to be statistically significant $(\mathrm{p}<0.05)$. In cases with arcus senilis, $61 \%$ of plaques were detected in common carotid artery gray scale ultrasonography, and $65 \%$ of them had soft character. There was also no statistically significant relationship between arcus senilis density and body mass index, smoking, neutrophil lymphocyte ratio, blood lipid profile $(\mathrm{p}>0.05)$.

\section{Conclusion:}

In corneal arcus senilis cases, it was observed that intima-media thickness and plaque formation increased in the common carotid artery. As well as more patients are needed, we can say that arcus senilis may be an independent risk factor for cardiovascular and cerebrovascular diseases.

Key Words: Arcus senilis, Carotid Arteries, Ultrasonography

\section{GIRIŞ}

Arkus senilis periferik korneada lipid depolanması ile karakterize dejeneratif bir değişikliktir (1). Korneal arkus, gerontokson, arkus juvenilis, anterior embriyotokson olarak da adlandırılır. Görülme sıklığı yaşla beraber artmaktadır ve 4 . dekadda $\% 14,7$. dekadda $\% 75$ oranında görülmektedir (1). Genellikle bilateraldir ve nadir de olsa tek taraflı olması aynı taraf karotis arter tıkanıklığını akla getirmelidir (2). Lipid depolanması klinik olarak gri-sarı bir yay şeklinde önce inferior korneadan başlar sonra süperior korneada görülür. Birikme ilerledikçe tam bir halka şeklini alır ve yoğunluğu artar. Bowman tabakasının kenarında saydam bir zon ile ayrıldığ için limbusa ilerleme olmaz. Lipid önce Descemet zarında sonra Bowman tabakasında depolanır ve ileri vakalarda stromal lameller arasında da birikir. Histopatolojik incelemede ekstrasellüler olarak kolesterol, kolesterol esterleri, fosfolipidler ve nötral gliseridlerin depolandığ görülmüştür. Bu depolanma vasküler kaynaklıdır ve düşük dansiteli lipoproteinin (LDL, low density lipoprotein) kapiller duvarı geçerek korneada birikmesi sonucu oluşmaktadır (3). Arkus senilisin anormal lipid seviyeleri ile ilişkisi bulunurken; aynı zamanda yaş, alkol alımı, sigara, Diabetes Mellitus, vücut kitle indeksi (VKI) ile ilişkisi yapılan çalışmalarda gösterilmiş (4-8). Günümüzde arkus senilisin kardiyovasküler hastalıklarla ilişkisini inceleyen çalışmalar vardır $(9,10)$. Fakat yapılan çalışmalarda arkus senilisin koroner kalp hastalıkları için bağımsız bir risk faktörü olup olamayacağı tam olarak ortaya konulamamıştır.

Biz de bu prospektif çalışmada korneal arkus senilis olan hastalarda tam kan sayımı ve kan lipid profili ile beraber ana karotis arterin (AKA) gri skala ultrasonografi (US) ve spektral analizli renkli doppler ultrasonografi (RDUS) ile değerlendirilmesini yaptık.

\section{GEREÇ ve YÖNTEMLER}

Prospektif olarak yapılan bu çalışma Şubat 2019- Ağustos 2019 tarihleri arasında yapıldı. Çalışmanın etik kurul onayı, 18.09.2019 tarihinde, 26379996-107 protokol numarası ile Yıldırım Beyazıt Üniversitesi Tıp Fakültesi Klinik Araştırmalar Etik Kurulu'ndan alındı. Tüm araştırma Helsinki Deklarasyon kurallarına uygun şekilde yürütüldü. Çalışmaya katılan tüm hastalardan bilgilendirilmiş onam formu alındı. Çalışmaya dahil edilen hastalar, rutin göz muayenesi esnasında korneal arkus senilisi olan hastalar arasından randomize olarak seçildi. Çalışmaya korneal distrofi, skar, pannus, posterior embriyotokson, vernal keratokonjonktivite sekonder psödogerontokson, pterjium, refraktif cerrahi, topikal ilaç kullanımı, romatolojik hastalık öyküsü olanlar dahil edilmedi. Arkus senilisin derecesi biyomikroskopik olarak hafif, orta ve yoğun şekilde aynı göz hekimi tarafından (YYT) sınıflandırıldı. Çalışmaya dahil edilen arkus senilisli hastalara yine aynı göz hekimi tarafından görme keskinliği, Goldmann applanasyon tonometresi ile göz içi basınc1, biyomikroskop ile ön segment, dilate fundus muayeneleri, VKİ hesabı, sigara kullanım öyküsü, tam kan sayımı, kan lipid profili (total kolesterol, trigliserid (TG), yüksek dansiteli lipoprotein (HDL, high density lipoprotein), LDL, çok düşük dansiteli lipoprotein (VLDL, very low density lipoprotein) değerlendirilmesi yapıldı.

Çalışmaya dahil edilen tüm hastalara deneyimli aynı radyo$\log$ (ÖÜ) tarafından sağ ve sol AKA'nın LOGIQ E9 GE (General Electric, Healthcare, USA) US cihazı ile incelenmesi yapıldı. Ölçümlerde yüksek rezolüsyonlu ML 6-15 MHz linear prob kullanıldı. Karotis arterleri önce gri skala US (B-mod inceleme) ile değerlendirildi sonra da sırasıyla RDUS ve spektral doppler US ile değerlendirildi. Hasta sirt üstü yatar pozisyondayken boynunu, görüntülenmekte olan tarafın karşıt yönüne doğru 45 derece kadar döndürüldü. Transdüser, sternokleidomastoid kasın ön tarafina yerleştirildi. Transdüserin yönü ile damar duvarının yönü birbirlerine paralel hale getirildi. Transvers ve longitudinal planda inceleme yapıldı. Karotis arterlerin görüntülenmesinde klavikulanın hemen üzerinden incelemeye başlandı ve karotislerin ikiye ayrıldığ 1 yere kadar devam ettirildi. İlk inceleme olan gri skala incelemede intima-media kalınlığı (IMK), karotis arter sistemindeki plaklar ve darlıklar değerlendirildi. İntima-media kalınlığı ölçümü ideal olarak karotis ayrılmasından yaklaşık $1 \mathrm{~cm}$ önceki AKA'dan, arterin en kalın olduğu yerden ve arka duvardan ölçüldü. Ana karotis arter arka duvarının lümen-intima ve media-adventisya sınırları çift çizgi olacak şekilde görüntülendi. Daha sonra arter lümeninin doluşunu görmek için renkli doppler görüntülemeden faydalanıldı. En son olarak da spektral 
Korneal Arkus Senilis Olgularında, Gri Skala ve Spektral Doppler Ultrasonografi ile Karotis Arter Değerlendirilmesi

doppler US incelemesi yapıldı. Bu inceleme ile karotis arterin non-invaziv anatomik ve hemodinamik değerlendirilmesi yapıldı. Karotis arterlerin darlık bölgesindeki akım hızının uygun değerlendirilmesi için transdüser yönü ve kan akımının yönü arasındaki açı 30-60 derece arasında idi.

İstatistiksel Değerlendirme elde edilen veriler SPSS 21.0 (Statistical Package for the Social Sciences, IBM) ve MedCalc (MedCalc Software version 12.3 bvba, Inc.) ortamında bilgisayara kaydedildi. Verilerin normal dağılımı Kolmogrov Smirnov testi ile değerlendirildi ve verilerin ortalaması, standart sapması hesaplandı. Elde edilen verilerin karşılaştırılması için non-parametrik testlerden Ki kare, Mann-Whitney U ve Kruskal Wallis testleri uyguland. Ölçümler arasındaki korelasyon için Pearson Korelasyon analizi kullanıldı. Değerlendirmeler \%95 güven aralığında yapıldı, p değerinin 0.05 den küçük olması istatistiksel anlamlı fark olarak kabul edildi.

\section{BULGULAR}

Çalışmaya 32 hastanın 64 gözü dahil edildi ve ortalama yaş $64,6 \pm 9,5$ (49-85) y1l ve kadın erkek oranı 10 (\%30) / 22 (\%70) idi. Ön segment muayenesinde, hastaların 22 (\%69)'si doğal iken (arkus senilis dişında), ikisinde (\%7) bilateral katarakt, yedisinde (\%22) bilateral göz içi lensi mevcuttu. Dilate fundus muayenesinde ise iki (\%7) hastanın tek taraflı epiretinal membranı tespit edildi. Hastaların ortalama görme keskinliği Snellen eşeline göre $0,97 \pm 0,10 \quad(0,4-1,0)$ düzeyinde, ortalama göz içi basıncı 14,43 $\pm 3,2$ (8-23) $\mathrm{mmHg}$ idi. Tüm gözlerde arkus senilis bilateral, halka şeklindeydi ve hafif, orta, yoğun arkus senilis oranı sırasıyla \%22 (14 göz), \%26 (17 göz), \%52 (33 göz) idi.

Arkus senilis olan hastaların özellikleri ve laboratuvar sonuçları Tablo I'de verilmektedir.

Hastaların tam kan sayımından hesaplanan nötrofil /lenfosit oranı (NLO) normal sinırlardaydı (Tablo I). Arkus senilisli hastaların referans değerlere göre kandaki total kolesterol, TG, LDL, VLDL değerleri yüksek, HDL değerleri düşüktü (Tablo I).

Tablo I. Korneal arkus senilisi olan hastaların özellikleri ve laboratuvar sonuçları

\begin{tabular}{|lc|}
\hline Sistemik hastalık olmayan & Hasta sayısı \\
\hline HT & $13(\% 41)$ \\
\hline DM & $5(\% 16)$ \\
\hline HT + DM & $4(\% 12)$ \\
\hline HT + KAH & $1(\% 3)$ \\
\hline Hiperkolesterolemi & $3(\% 9)$ \\
\hline & $6(\% 19)$ \\
\hline VKİ $\left(\mathbf{k g} / \mathbf{m}^{2}\right)$ & Ortalama \pm SD (min-maks) \\
\hline Sigara (paket/yl) & $26,21 \pm 5,07(11,11-36,79)$ \\
\hline Nötrofil /Lenfosit & $0,5 / 17,5$ \\
\hline Kolesterol (mg/dL) & $2,18 \pm 0,86(0,99-5,08)$ \\
\hline TG $(\mathbf{m m o l} / \mathbf{L})$ & $228,11 \pm 54,96(113-343)$ \\
\hline HDL $(\mathbf{m m o l} / \mathbf{L})$ & $193,94 \pm 125,75(64-634)$ \\
\hline LDL $(\mathbf{m m o l} / \mathbf{L})$ & $50,05 \pm 9,44(38-68)$ \\
\hline VLDL $(\mathbf{m m o l} / \mathbf{L})$ & $143,87 \pm 49,74(51-261)$ \\
\hline
\end{tabular}

HDL: High density lipoprotein, HT: Hipertansiyon, DM: Diabetes Mellitus, KAH: Koroner arter hastalığ1, LDL: Low density lipoprotein, TG: Trigliserid, VKİ: Vücüt kitle indeksi, VLDL: Very low density lipoprotein.
Hastaların AKA gri skala US ve RDUS sonuçları Tablo II'de verilmektedir. Arkus senilisli hastalara yapılan AKA gri skala US'de ortalama İMK 1,22 $\pm 0,27$ mm idi (Tablo II). Hastaların gri skala US'sinde $\% 61$ oranında plak tespit edildi ve bunların \%65'i yumuşak karakterliydi (Tablo II). AKA'nın RDUS ile ölçülen hemodinamik parametreleri ise normal sinırlardaydı (Tablo II).

Tablo II. Korneal arkus senilisi olan hastaların ana karotis arter gri skala ultrasonografi ve renkli doppler ultrasonografi sonuçları

\begin{tabular}{|lc|} 
& Ortalama \pm SD $($ min-maks) \\
\hline IMK & $1,22 \pm 0,27(0,8-2,10)$ \\
\hline Plak & $25(\% 39)$ yok \\
& $39(\% 61)$ var \\
\hline Plak cinsi (kalsifik/yumuşak) & $14(\% 35) / 25(\% 65)$ \\
\hline Plak boyutu (mm, boy x en) & $11,29 \pm 7,38(2,50-34,20) \times$ \\
& $3,1 \pm 3,86(1,30-18,0)$ \\
\hline Peak sistolik hız (cm/sn) & $72,72 \pm 15,34(43,7-120,3)$ \\
\hline End diastolik hız (cm/sn) & $22,80 \pm 5,24(15,0-37,70)$ \\
\hline Peak sistolik hız/ & $3,22 \pm 0,38(2,40-4,10)$ \\
\hline end diastolik hız & \\
\hline Rezistif indeks & $0,68 \pm 0,036(0,62-0,76)$ \\
\hline
\end{tabular}

İMK: İntima-media kalınlığı.

Arkus senilisin yoğunluğuna göre AKA'da US verilerinin değerlendirilmesi Tablo III'te verilmektedir. Arkus senilisin yoğunluğu arttıkça İMK'nin arttığı gözlendi ve yoğun arkus senilis olanlarda İMK'nın hafif ve orta yoğunluktaki arkus senilisli olanlara göre yüksek olması istatistiksel olarak anlamlı bulundu $(\mathrm{p}<0.05)$ (Tablo III). Arkus senilis yoğun olanlarda plak varlığının da yüksek olması istatistiksel olarak anlamlılık gösterdi ( $\mathrm{p}=0,049)$ (Tablo III). Diğer US bulguları ile AS yoğunluğu arasında istatistiksel olarak anlamlı farkl1lık görülmedi ( $\mathrm{p}>0.05)$ (Tablo III).

Tablo III. Korneal arkus senilisin yoğunluğuna göre ana karotis arterin gri skala ultrasonografi ve renkli doppler ultrasonografik verileri

\begin{tabular}{|c|c|c|c|c|}
\hline & Hafif AS & Orta AS & $\begin{array}{l}\text { Yoğun } \\
\text { AS }\end{array}$ & p \\
\hline AKA (n) & 14 & 17 & 33 & \\
\hline IMK & $\begin{array}{l}1,05 \pm 0,15 \\
(0,80-1,30)\end{array}$ & $\begin{array}{l}1,10 \pm 0,14 \\
(0,90-1,30)\end{array}$ & $\begin{array}{l}1,35 \pm 0,30 \\
(1,0-2,10)\end{array}$ & $\begin{array}{l}\text { Hafif-orta AS: 0,418 } \\
\text { Orta -yoğun AS: } 0,005 \\
\text { Hafif-yoğun AS: 0,016 }\end{array}$ \\
\hline Plak & $\begin{array}{l}10(\% 70) \text { yok } \\
4(\% 30) \text { var }\end{array}$ & $\begin{array}{l}7(\% 42) \text { yok } \\
10(\% 58) \text { var }\end{array}$ & $\begin{array}{c}8(\% 25) \\
\text { yok } \\
25(\% 75) \\
\text { var }\end{array}$ & $\mathbf{0 , 0 4 9}$ \\
\hline $\begin{array}{l}\text { Peak sistolik hiz } \\
\text { (cm/sn) }\end{array}$ & $\begin{array}{c}68,44 \pm 13,03 \\
(43,7-88,5)\end{array}$ & $\begin{array}{c}72,88 \pm 17,54 \\
(55,3-120,3)\end{array}$ & $\begin{array}{c}74,43 \\
\pm 15,36 \\
(47,7 \\
103,1)\end{array}$ & 0,592 \\
\hline $\begin{array}{l}\text { End diastolik hy } \\
\text { (cm/sn) }\end{array}$ & $\begin{array}{l}22,7 \pm 4,12 \\
(17,5-31,4)\end{array}$ & $\begin{array}{l}22,96 \pm 5,62 \\
(16,2-36,3)\end{array}$ & $\begin{array}{c}22,85 \\
\pm 5,64 \\
(15-37,7)\end{array}$ & 0,987 \\
\hline $\begin{array}{l}\text { Peak sistolik huz/ } \\
\text { end diastolik hhz }\end{array}$ & $\begin{array}{l}3,07 \pm 0,52 \\
(2,40-4,10)\end{array}$ & $\begin{array}{l}3,19 \pm 0,32 \\
(2,63-3,80)\end{array}$ & $\begin{array}{l}3,29 \pm 0,34 \\
(2,70-4,0)\end{array}$ & 0,283 \\
\hline Rezistif indeks & $\begin{array}{l}0,67 \pm 0,04 \\
(0,62-0,76)\end{array}$ & $\begin{array}{l}0,68 \pm 0,03 \\
(0,62-0,74)\end{array}$ & $\begin{array}{l}0,69 \pm 0,03 \\
(0,63-0,75)\end{array}$ & 0,384 \\
\hline
\end{tabular}

AKA: Ana karotis arter, AS: Arkus senilis,

İMK: İntima-media kalınlığı. 
Yıldız Taşçı Y. ve Ünal Ö.

Arkus senilisi yoğun olan bir hastanın ön segment fotoğrafi, gri skala US ve spektral analizli RDUS görüntüsü Şekil 1'de görülmektedir.

Şekil 1: Korneal arkus senilisi yoğun olan bir hastanın ön segment biyomikroskopik görüntüsü (a), aynı hastanın gri skala ultrasonografi incelemesinde ana karotis arter intima-media kalınlığ 1 (b), kırmızı ok: İntima-media kalınlığı $(1.4 \mathrm{~mm})$, spektral analizli renkli doppler ultrasonografi görüntüsü (c).
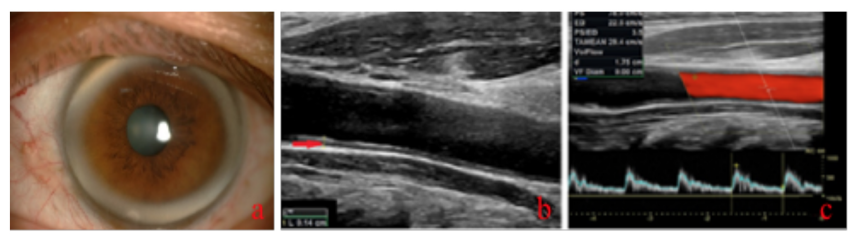

Arkus senilis yoğunluğu ile VKİ, sigara kullanımı, NLO ve kan lipid profilleri arasında istatistiksel olarak anlamlı bir ilişki bulunmadı $(\mathrm{p}>0.05)$. Hastaların lipid profilleri ile gri skala US, RDUS değerleri arasında yapılan Pearson Korelasyon analizi Tablo IV'te verilmektedir. Kandan ölçülen total kolesterol ve LDL değerleri ile AKA plak boyutları arasında anlamlı korelasyon görüldü (Tablo IV).

Tablo IV. Korneal arkus senilisi olan hastaların lipit profilleri ile ana karotis arterin gri skala ultrasonografi ve renkli doppler ultrasonografik değerleri arasındaki Pearson Korelasyon analizi

\begin{tabular}{|c|c|c|c|c|c|c|}
\hline & & Kolesterol & $\underset{(\mathrm{mmo} / \mathrm{L})}{\mathrm{TG}}$ & $\underset{(\mathrm{mmol} / \mathrm{L})}{\mathrm{HIL}}$ & $\underset{(\mathbf{m m o} / / \mathbf{L})}{\mathrm{LDL}}$ & $\begin{array}{c}\text { VLDL } \\
(\mathrm{mmol} / \mathrm{L})\end{array}$ \\
\hline İMK & $\underline{\underline{r}}$ & 0,130 & $-0,029$ & $-0,187$ & 0,449 & $-0,072$ \\
\hline Plak boyutu (boy, mm) & $\begin{array}{l}\underline{p} \\
\underline{\underline{r}} \\
\underline{p}\end{array}$ & $\begin{array}{l}0,620 \\
0,525 \\
0,097\end{array}$ & $\begin{array}{c}0,912 \\
-0,071 \\
0,836\end{array}$ & $\begin{array}{c}0,458 \\
-0,135 \\
0,676\end{array}$ & $\begin{array}{l}0,093 \\
0,743^{*} \\
\mathbf{0 , 0 2 2}\end{array}$ & $\begin{array}{l}0,777 \\
-0,079 \\
0,808\end{array}$ \\
\hline Plak boyutu (en, mm) & $\underline{\underline{\underline{r}}}$ & $\begin{array}{l}0,642^{*} \\
0,025\end{array}$ & $\begin{array}{c}-0,090 \\
0,81\end{array}$ & $\begin{array}{r}-0,354 \\
0,235\end{array}$ & $\begin{array}{l}0,790^{* *} \\
0,007\end{array}$ & $\begin{array}{r}-0,068 \\
0,826\end{array}$ \\
\hline Peak sistolik hlz (cm/sn) & $\underline{\underline{\underline{r}}}$ & $\begin{array}{c}-0,180 \\
0,489\end{array}$ & $\begin{array}{l}0,082 \\
0,754\end{array}$ & $\begin{array}{c}-0,341 \\
0,166\end{array}$ & $\begin{array}{r}-0,340 \\
0.216\end{array}$ & $\begin{array}{l}0,132 \\
0,602\end{array}$ \\
\hline End diastolik hyz (cm/sn) & $\underline{\underline{\underline{r}}}$ & $\begin{array}{c}-0,074 \\
0,777\end{array}$ & $\begin{array}{l}0,149 \\
0,567\end{array}$ & $\begin{array}{c}-0,286 \\
0,251\end{array}$ & $\begin{array}{c}-0,254 \\
0.360\end{array}$ & $\begin{array}{l}0,192 \\
0,444\end{array}$ \\
\hline Rezistif indeks & $\underline{\underline{\underline{r}}}$ & $\begin{array}{l}-0,185 \\
0,476\end{array}$ & $\begin{array}{r}-0,085 \\
0,746\end{array}$ & $\begin{array}{c}-0,111 \\
0,662\end{array}$ & $\begin{array}{l}-0,181 \\
0,517\end{array}$ & $\begin{array}{c}-0,073 \\
0,775\end{array}$ \\
\hline
\end{tabular}

HDL: High density lipoprotein, İMK: İntima-media kalınlığı, LDL: Low density lipoprotein, TG: Trigliserid,

VLDL: Very low density lipoprotein, , r: Korelasyon katsayıs1, *: p değeri 0.01 düzeyinde anlamlı korelasyon, **: p değeri 0.05 düzeyinde anlamlı korelasyon.

\section{TARTIŞMA}

Biyomikroskop ile tanı konulan arkus senilis korneada lipid depolanması ile karakterize dejeneratif bir durumdur. Arkus senilisin sadece kandaki yüksek kolesterolden kaynaklanan bir görüntü mü veya kardiyovasküler hastalıklar için bir risk faktörü mü, bu sorunun cevabı 100 yıldan fazladır tartışılmaktadır (11). Aterosklerotik hastalıkların vücuttaki görsel bulgularından Frank işareti (diyagonal kulak memesi kıvrımı) ve ksantelazma ile beraber arkus senilis de yer almaktadır (12). Arkus senilisin görülme sıklığı yaş ile artarken genç hastalarda (35 yaşından önce parsiyel, 50 yaşından önce halka şeklinde) görülmesi ailevi hiperkolesterolemiyi düşündürmelidir ve nadir de olsa lesitin kolesterol açil transferaz eksikliği ile seyreden Fish-eye hastalığında da erken yaşta görülebilir $(13,14)$.

Yapılan bazı çalışmalar arkus senilisin kardiyovasküler hastalıklar için bir risk faktörü olduğunu desteklerken, bazı çalışmalar ise bu görüşü desteklememektedir (8,15-17).

Önceden yapılan çalışmalarda arkus senilisin yüksek kan lipid düzeyi ile ilişkili olduğu gösterilmiştir $(5,9)$. Bizim çalışmamızda da bu çalışmalarla uyumlu olacak şekilde arkus senilis olgularının kandaki total koleterol, TG, LDL, VLDL değerleri yüksek, HDL değeri düşük ölçülmüştür. Kardiyovasküler hastalık ile inflamasyon arasındaki ilişki önceki çalışmalarda incelenmiş ve plak formasyonunda ve ateroskleroz progresyonunda inflamasyonun rol oynadığı bulunmuştur (9). Arkus senilis ile C-reaktif protein (CRP) ilişkisini değerlendiren bir çalışmada CRP ile arkus senilis arasında anlamlı ilişki tespit edilmiş (9). Bizim çalışmamızda arkus senilisli olgularda inflamasyonun bir bulgusu olan NLO'yu değerlendirdik ve arkus senilisli olgularda NLO'yu normal sinırlarda bulduk. Ancak inflamasyon ile arkus senilis arasında ilişki olup olmadığını göstermek için daha geniş hasta popülasyonuna ihtiyaç vardır.

Renyi ve ark.'nın (9) Asya popülasyonunda yaptığı bir çalışmada arkus senilisli olgularda, periferik arter hastalıkları ve kronik böbrek hastalığı açısından değerlendirme yapılmış ve sonucunda da arkus senilisli olgularda hiperkolesterolemi, periferik arter hastalığı ve kronik böbrek hastalığı ile ilişkisi olabileceği öne sürülmüştür. Aynı zamanda 50 yaş üzerindeki hastalarda periferik arter hastalığı ile arkus senilis arasında bağımsız bir ilişki bulmuşlardır ve arkus senilisli erkek hastalarda ve 50 yaş üzerinde kronik böbrek hastalığ görülme oranının daha yüksek olduğunu göstermişlerdir (9). Periferik arter hastalığı aterosklerotik bir hastalık olduğu için kardiyovasküler kaynaklı mortalite ve morbidite nedeni olarak görülmektedir. Bu nedenle arkus senilis ile kardiyovasküler hastalıklar ilişkilendirilmektedir. Wong ve ark.'nın (18) yaptığı bir çalışmada 40-80 yaş arası Asya popülasyonunda, 6 y1llık takiplerinde yeni gelişen kardiyovasküler hastalık, miyokard infarktüs, anjina pektoris ve inme açısından değerlendirilme yapılmış. Bu 6 yıllık takipte arkus senilis olanlarda kardiyovasküler hastalık görülme oranı \%7.5 iken, olmayanlarda \%4.9 oranında ve arkus senilis olanlarda ortalama odds oranı erkek cinsiyetinde 1.73, kadın cinsiyetinde 1.05 düzeyinde bulunmuş (18). Bu çalışmanın sonucunda da özellikle erkek hastalarda kardiyovasküler hastalıklar için olan kan lipid düzeyi ve geleneksel risk faktörlerinden bağımsız olarak arkus senilis varlığı yeni kardiyovasküler hastalık ile ilişkilendirilmiş ve erkek hastalarda arkus senilisin kardiyovasküler hastalık için bir işaret olduğu öne sürülmüştür (18). Ang ve ark.'nın (19) yaptığg bir çalışmada ise 40-80 yaş arası arkus senilis görülme oran $1 \% 50,1$ oranında olup; ileri yaş, erkek cinsiyet, yüksek total kolesterol ve sigara kullanımı olanlarda daha fazla gözlenmiş ve arkus senilis için kardiyovasküler hastalıklar ile arasında bağımsız bir risk faktörü olabileceği öne sürülmüştür.

Mette ve ark.'nın (20) yaptığı bir çalışmada, 30 yıllık süre içerisinde gelişen miyokard infarktüsü, iskemik stroke, serebrovasküler olay ve ölüm durumlarında hastaların ksantalezma, arkus senilis varlığ değerlendirilmiş ve ksantelazma ile iskemik olaylar arasında anlamlı bir ilişki tespit edilirken, arkus senilis ile bir ilişki kurulamamıştır. Literatürde bilateral arkus senilisi olan hastalarda karotis arteri değerlendiren tek bir çalışmaya rastlanmıştır ve bu 
Korneal Arkus Senilis Olgularında, Gri Skala ve Spektral Doppler Ultrasonografi ile Karotis Arter Değerlendirilmesi

çalışmada bizim çalışmamızla uyumlu olacak şekilde arkus senilisli olgularda karotis arter İMK'nın normalden daha kalın olduğu gösterilmiştir (21). ARIC çalışmasında (Atherosclerosis Risk In Communities Study), yaş, ırk, diyabet, hiperkolesterolemi, hipertansiyon ve sigara gibi risk faktörleri olmadan bile, karotis İMK ile akut miyokart enfarktüsü geçirme riski arasında güçlü bir ilişki bulunmuştur (22). Lorenz ve ark.'nın (23) yapmış oldukları bir çalışmada IMK'deki her 0,1 mm'lik artışın miyokart enfarktüsü ve iskemik serebrovasküler olay geçirme risk oranını $\% 5$ yükselttiği gözlemlenmiştir. Benzer şekilde Yao City çalışmasında, karotis İMK ölçümü ile miyokart enfarktüsü, serebrovasküler olay ve kardiyovasküler kaynaklı ölüm arasında güçlü bir ilişki bulunmuştur (24). AKA'de İMK'nın normal kalınlığı 0,8 mm'dir (25). Bizim çalışmamızda arkus senilis olan hastalarda ortalama İMK 1,22 mm bulduk ve arkus senilis yoğunluğunun artmasıyla İMK'nın arttığını gözlemledik. Bu da bize özellikle yoğun arkus senilisi olan olguların kardiyovasküler ve serebrovasküler hastalık riski oluşturması açısından ayrıca önem taşıdığını göstermektedir. Bizim çalışmamızda arkus senilisli hastalarda \%61 oranında plak tespit ettik. Bununla beraber yumuşak karekterli plakların (ekojenitesi düşük ekolüsen), kalsifiye plaklara (ekojenitesi fazla) oranla daha fazla görüldüğünü ve arkus senilisin yoğunluğunun artmasıyla plak görülme oranının arttığını gözlemledik. Yumuşak plaklar fibröz yağlı plaklar olup lipid içeriği yüksek plaklardır. Bu nedenle arkus senilis olgularında kandaki yüksek kolesterol düzeyleri nedeniyle yumuşak plak görülmesi beklenen bir durumdur.

\section{Çalışmanın Kısıtlılıkları:}

Ön segment biyomikroskop ile yapılan arkus senilis sınıflandırmasının, ön segment fotoğrafı veya ön segment optik koherens tomografi gibi daha objektif yöntemlerle yapılamamış olması ve cinsiyet gibi alt gruplar arası karşılaştırmanın değerlendirilebilmesi için daha geniş seride hasta sayısına ihtiyacın olması bu çalışmanın kısıtlılıklarını oluşturmaktadir.

\section{SONUÇ}

Korneal arkus senilis kandaki yüksek kolesterol seviyesinin görsel bir bulgusu olarak karşımıza çıkmaktadır. Arkus senilis olan olgularda AKA'da her ne kadar hemodinamik parametreler değişmese de, İMK artmakta ve plak oluşumu gözlenmektedir. $\mathrm{Bu}$ nedenle kardiyovasküler ve serebrovasküler hastalıklara bağlı mortalite ve morbiditeyi azaltmak için, daha fazla hasta popülasyonu ile desteklenmeye ihtiyaç duymakla beraber, korneada arkus senilis varlığı daha önemli bir klinik bulgu haline gelebilir; ileri çalışmaların da desteklemesi durumunda kardiyovasküler ve serebrovasküler hastalıklar için bağımsız bir risk faktörü olabilir.

Etik Komite Onayı: Bu araştırma, ilgili tüm ulusal düzenlemelere, kurumsal politikalara ve Helsinki Bildirgesinin ilkelerine uygundur ve Yıldırım Beyazıt Üniversitesi Yıldırım Beyazıt Tıp Fakültesi Etik Kurulu tarafından onaylanmıştır (onay numarası: 2019 / 26379996-107).

Hasta Onamı: Tüm katılımcıların hakları korunmuş ve Helsinki Deklarasyonuna göre prosedürlerden önce yazılı bilgilendirilmiş onam alınmıştır.

Yazar Katkıları: Fikir -Y.Y.T., Ö.Ü.; Tasarım - Y.Y.T., Ö.Ü.; Denetleme - Y.Y.T., Ö.Ü.; Kaynaklar - Y.Y.T.; Malzemeler Y.Y.T., Ö.Ü.; Veri Toplanması ve/veya İşlemesi - Y.Y.T., Ö.Ü.; Analiz ve/veya Yorum - Y.Y.T., Ö.Ü.; Literatür Taraması - Y.Y.T.; Yazıyı Yazan - Y.Y.T.; Eleştirel İnceleme Y.Y.T., Ö.Ü.

Çıkar Çatışması: Yazarların beyan edecek çıkar çatışması yoktur.

Finansal Destek: Yazarlar bu çalışma için finansal destek almadıklarını beyan etmişlerdir. 


\section{KAYNAKLAR}

1. Friedlander MH, Smolin G. Corneal degenerations. Ann Ophthalmol 1979; 11:1485.

2. Sugimura G. Unilateral corneal arcus. Arch Ophthalmol 1990; 108:780.

3. Coşar B. Korneanın keratokonus dıșı dejeneratif hastalıkları. Tamçelik N, ed. Kornea, 1. Baskı, Türk Oftalmoloji Derneği Eğitim Yayınları No:11, İstanbul, 2009:237-8.

4. Rifkind BM, Dickson C. The incidence of arcus senilis in ischemic heart disease, its relation to serum-lipid levels. Lancet 1965: 312-4.

5. Hickey N, Maurrer B, Mulcahy R. Arcus senilia: its relation to certain attributes and risk factors in patients with coronary artery disease. Br Med J 1970; 32:449-52.

6. Chua BE, Mitchell P, Wang J, Rochtchina E. Corneal arcus and hyperlipidemia: findings from an older population. Am J Ophthalmol 2004; 137:363-5.

7. Barchiesi BJ, Eckel RH, Ellis PP. The cornea and disorders of lipid metabolism. Surv Ophthalmol 1991; 36:1-22.

8. Chambless LE, Fuchs FD, Linn S, Kritchevsky SB, Larosa JC, Segal P, Rifkind BM. The association of corneal arcus with coronary heart disease and cardiovascular disease mortality in the Lipid Research Clinics Mortality Follow-up Study. Am J Public Health 1990; 80:1200-4.

9. Wu R, Wang JJ, Tai ES, Wong TY. Cardiovascular risk factors, inflammation, and corneal arcus: the singapore malay eye study. Am J Ophthalmol 2010; 150:581-7.

10. Fernandez A, Sorokin A, Thompson PD. Corneal arcus as coronary artery disease risk factor. Atherosclerosis 2007; 193:235-40.

11. Virchow VR. Uber parenchymatose entzundun. Virchows Arch Pathol Anat 1852; 4:261.

12. Baboujian A, Bezwada P, Ayala-Rodriguez C. Diagonal Earlobe Crease, a Marker of Coronary Artery Disease: A Case Report on Frank's Sign. Cureus 2019; 11:4219.

13. Lock JH, Ross CA, Flaherty M. Corneal arcus as the presenting sign of familial hypercholesterolemia in a young child. $\mathrm{J}$ AAPOS 2018; 22:467-8.

14. Mayalı H, Kılıç Ş, Cansız Ç, Türkoğlu MŞ, Başer EF. Corneal Haze and Peripheral Corneal Arcus in a Young Patient: Lecithin-Cholesterol Acyltransferase Deficiency. Turkish Journal of Ophthalmology 2014; 44:319-21.

15. Hoogerbrugge N, Happee C, van Domburg R, Poldermans $\mathrm{D}$, van den Brand MJ. Corneal arcus: indicator for severity of coronary atherosclerosis? Neth J Med 1999; 55:184-7.

16. Fernandez AB, Keyes MJ, Pencina M, D'Agostino R,O'Donnell CJ, Thompson PD. Relation of corneal arcus to cardiovascular disease (from the Framingham Heart Study data set). Am J Cardiol 2009; 103:64-6.

17. Dikmetaş Ö, Mocan MC, Sevim DG, İrkę̧ M. The association of arcus senilis with exfoliation syndrome and cardıovascular disease in elderly population. Turkish Journal of Geriatrics 2015; 18:36-41.

18. Wong MYZ, Man REK, Gupta P, Lim SH, Lim B, Tham YC, Sabanayagam C, Wong TY, Cheng CY, Lamoureux EL. Is Corneal Arcus Independently Associated With Incident Cardiovascular Disease in Asians? Am J Ophthalmol 2017; 183:99-106.

19. Ang M, Wong W, Park J, Wu R, Lavanya R, Zheng Y, Cajucom-Uy H, Tai ES, Wong TY. Corneal arcus is a sign of cardiovascular disease, even in low-risk persons. Am J Ophthalmol 2011; 152:864-71.

20. Christoffersen M, Frikke-Schmidt R, Schnohr P, Jensen GB, Nordestgaard BG, Tybjærg-Hansen A. Xanthelasmata, arcus corneae, and ischaemic vascular disease and death in general population: prospective cohort study BMJ 2011; 15;343.

21. Rouhiainen P, Salonen R, Rouhiainen H, Salonen JT. Association of corneal arcus with ultrasonographically assessed arterial wall thickness and serum lipids. Cornea $1993 ; 12: 142-5$.

22. Nambi V, Chambless L, Folsom AR, He M, Hu Y, Mosley T, Volcik K, Boerwinkle E, Ballantyne CM. Carotid intima-media thickness and presence or absence of plaque improves prediction of coronary heart disease risk: the ARIC (Atherosclerosis Risk In Communities) study. J Am Coll Cardiol 2010; 55:1600-7.

23. Lorenz MW, Markus HS, Bots ML, Rosvall M, Sitzer M. Prediction of clinical cardiovascular events with carotid intima-media thickness: a systematic review and metaanalysis. Circulation 2007; 115:459-67.

24. Kitamura A, Iso H, Imano H, Ohira T, Okada T, Sato S, Kiyama M, Tanigawa T, Yamagishi K, Shimamoto T. Carotid intima-media thickness and plaque characteristics as a risk factor for stroke in Japanese elderly men. Stroke 2004; 35:2788-94.

25. Tosetto A, Prati P, Baracchini C, Manara R, Rodeghiero F. Ageadjusted reference limits for carotid intima-media thickness as better indicator of vascular risk: population-based estimates from the VITA Project. J Thromb Haemost 2005; 3:1224. 